Viaje postMIR

\title{
Ya está hecho el examen MIR; ¿qué pasa ahora?
}

\author{
Alejandro de Gea Grela
}

Egresado de la 3ª promoción del Grado en Medicina de la Universidad de Alcalá (2012-2018)

5 horas. Eso es lo que dura el examen para el que has estado unos 8 meses dedicándote exclusivamente. Meses en los que la rutina era despertarse para estudiar, descansar brevemente para comer, volver a estudiar... y a dormir. Meses en los que valorabas cada hora de tiempo libre que (no siempre) podías conseguir. Ese año de tu vida en el que dabas gracias por conseguir unos escasos días en verano para ir a la playa a intentar quitarte ese color blanco radiactivo.

Son unos meses duros, agotadores, en los que tu vida social se reduce casi al máximo. Unos meses con altibajos, en los que parece que tu vida sólo gira en torno a netas, simulacros, manuales, vueltas... Pero, de repente, tras esas 5 horas, te das cuenta de que ya ha acabado: ¿qué pasa ahora?

Se entra en un período de relativa tranquilidad. El día a día cambia: pasas a tener todo el tiempo del mundo. Las preocupaciones cambian a elegir la ciudad donde vivir y trabajar durante los próximos años, qué especialidad escoger, elaborar la famosa lista. Te llenas la agenda de contactos de residentes de hospitales de toda España. Preguntas y preguntas y vuelves a preguntar. Pero también recuperas la vida social que habías perdido, retomas aficiones que habías dejado abandonadas y disfrutas de estos meses de libertad casi total antes de empezar la residencia.

De la noche a la mañana pasaremos de ser estudiantes a médicos residentes. La rutina no volverá a ser sentarse a estudiar bajo la luz del flexo. Ahora toca aprender a trabajar como médico, a tratar con pacientes, familiares, nuevos compañeros... En muchos casos, toca cambiar de casa, de ciudad. Tocará enfrentarse a las guardias, a dar malas noticias, a pasar por malos momentos, asumir responsabilidades.

Pero es una etapa que viene cargada de ilusión. Todas las nuevas amistades que se van a crear, todos los conocimientos que vamos a adquirir, vernos cada día más cerca de conseguir ser especialistas en aquello que hemos elegido. Hay muchas ganas de hacerlo bien, sabemos que van a venir etapas complicadas, pero que sin duda los buenos momentos que vamos a vivir las compensarán con creces.

Pero antes de todo esto, también hemos podido aprovechar las vacaciones para viajar. Desde España y Europa hasta Asia, pasando por América y África. Desde playas paradisiacas al frío y la nieve del norte. Viajes en grupos, de "mochileros", de cooperación... Viajes para visitar amigos, viajes en familia, improvisados o planeados... Cualquier excusa era buena para desconectar y descansar, descubrir nuevas partes del mundo, vivir experiencias y cargarnos de fuerza. Toda esta variedad de destinos y viajes es lo que intentamos resumir en esta colección de fotos, aunque no estén todos y cada uno de ellos.

Lo que sin duda nos queda claro es que estos viajes han supuesto un fantástico broche de oro final a lo que ha sido esta promoción de medicina UAH 2012-18. ¡Compañeros, ha sido un placer! Estoy seguro de que todos nosotros seguiremos sintiéndonos parte de esta pequeña gran familia que se formó durante estos 6 años. 


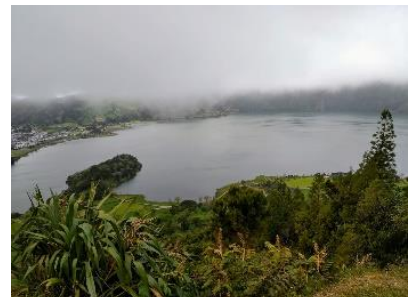

AZORES

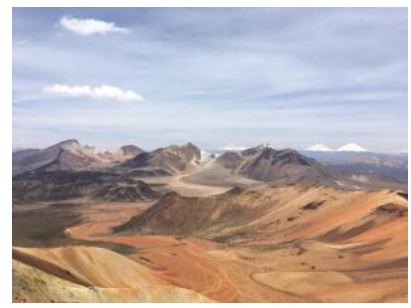

CHILE

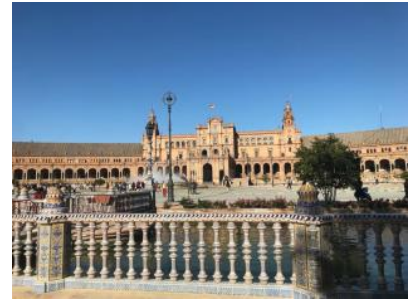

ESPAÑA

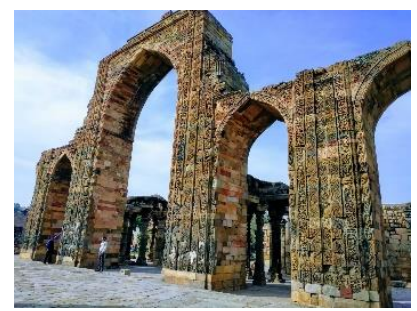

INDIA

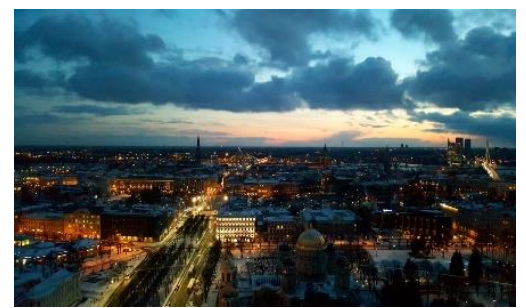

LETONIA

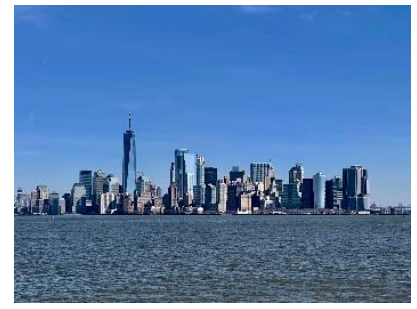

NUEVA YORK

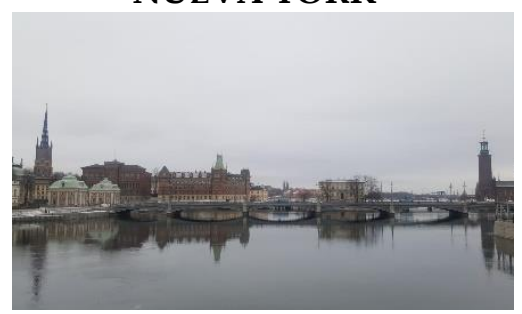

SUECIA

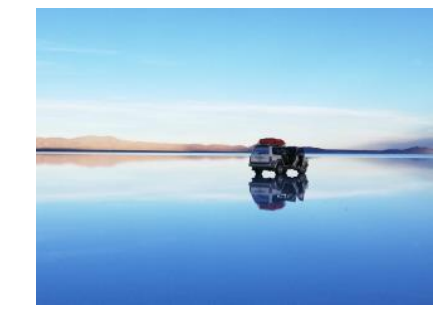

BOLIVIA

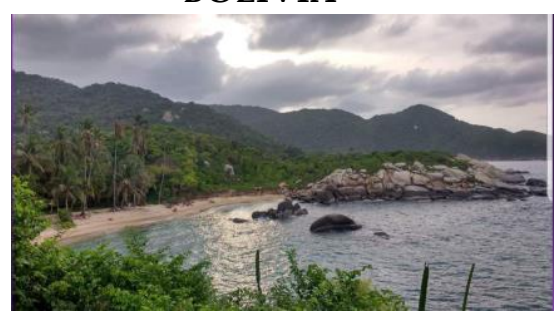

COLOMBIA
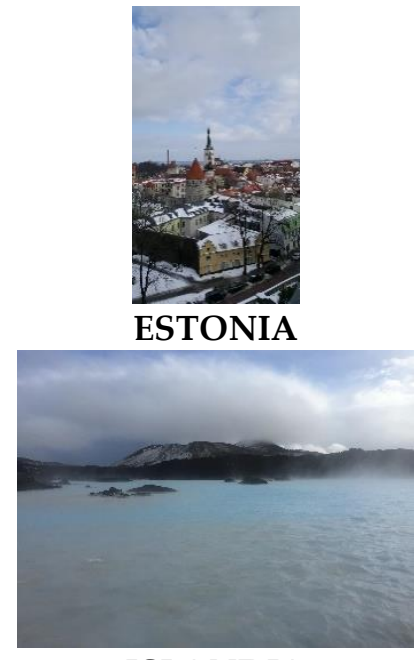

ISLANDIA

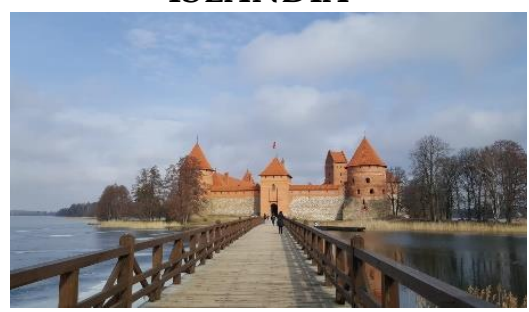

LITUANIA

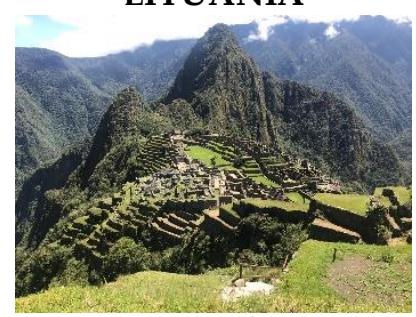

PERÚ

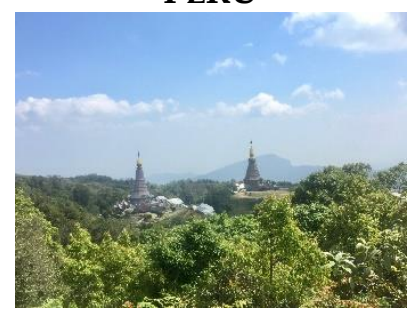

TAILANDIA

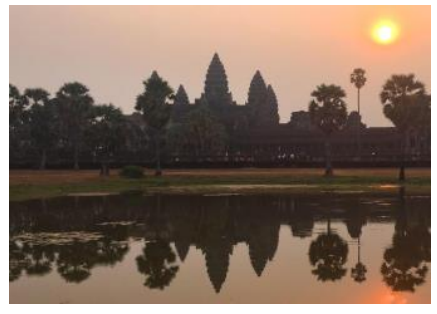

CAMBOYA

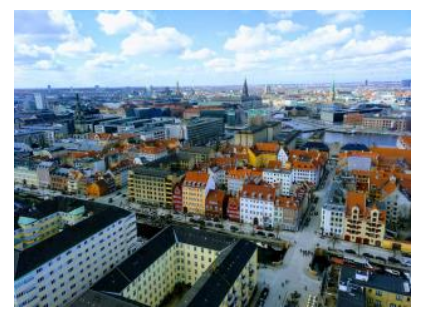

DINAMARCA

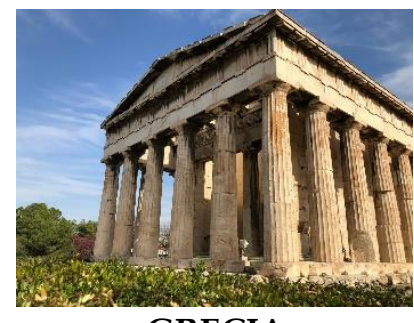

GRECIA

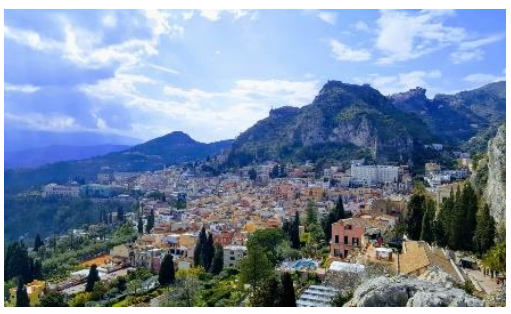

ITALIA

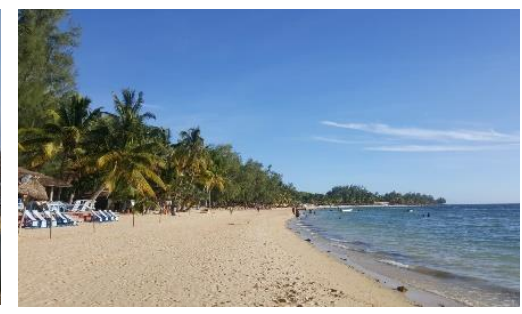

MADAGASCAR

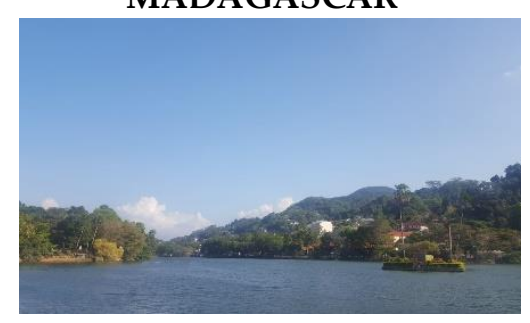

SRI LANKA

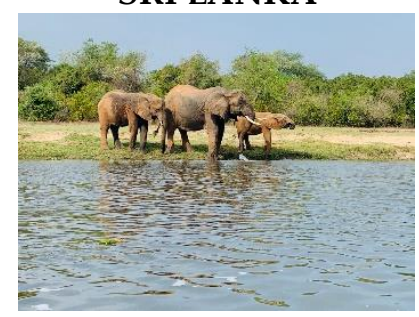

UGANDA 
(C) 2019 por los autores; Esta obra está sujeta a la licencia de Reconocimiento 4.0 Internacional de Creative Commons. Para ver una copia de esta licencia, visite http://creativecommons.org/licenses/by-nc-nd/4.0/. 